\title{
The problem of the demonstration of hepatitis B antigen in faeces and bile
}

\author{
J. W. MOODIE, LINDA M. STANNARD, AND A. KIPPS \\ From the MRC and University of Cape Town Virus Research Unit, Medical School, Cape Town, \\ South Africa
}

SYNOPSIS Attempts to detect hepatitis B antigen in faeces and bile should take into account the degradation and disappearance of the surface antigens in an environment containing proteolytic enzymes in the presence of bile salts as in the intestinal lumen. The cores of the Dane particles are much more stable than the surface antigens and these may best be identified by immune electron microscopy using core antibody.

The search for the elusive infectious virus responsible for hepatitis B led some investigators to look, not surprisingly, at faecal extracts and bile. While hepatitis B antigen (HB Ag) in the serum may enter the intestinal lumen by haemorrhage, a more likely source of faecal HB Ag is the bile since the association of HB Ag and its synthesis with the liver has for long been presumed and more recently confirmed (Huang and Groh, 1973), but attempts to demonstrate its presence in the faeces or bile of patients with antigenaemia or with acute hepatitis have given conflicting results. Using standard serological tests for the detection of HB Ag, Grob and Jemelka (1971) found them positive in faecal extracts of all 11 patients with acute hepatitis; Serpeau, Mannoni, Dhumeaux, and Berthelot (1971) found evidence of the antigen in bile (but not in duodenal juice) in two patients, and Akdamar, Maumus, Epps, Leach, and Warren (1971) showed the presence of the antigen in the bile of one of four patients, but not in the gastric juice of any of them. On the other hand, Cossart and Vahrman (1970) were unable to find the antigen in four faecal extracts from patients with acute hepatitis despite the fact that the extracts had been concentrated 100 -fold, and negative results were also reported on 47 faecal extracts from 15 patients examined by Gust, Kaldor, and Nastasi (1971). Grabow and Prozesky (1973a) failed to detect $\mathrm{HB}$ antigen in 12 faecal samples from patients with antigenaemia.

Many of these observations were made at a time before the general awareness of the existence of the two antigen-antibody systems in hepatitis B

Received for publication 23 May 1974.
(Almeida, Rubenstein, and Stott, 1971; Stannard Polson, Kipps, and Parker, 1973), and at a time when the effect of bile salts and proteolytic enzymes on the morphology and antigenic integrity of the surface antigen $\left(\mathrm{HB}_{\mathrm{s}} \mathrm{Ag}\right)$ or the 'core' antigen $\left(\mathrm{HB}_{\mathrm{c}} \mathrm{Ag}\right)$ was not known. The investigators could not have known then whether the antisera they used for the detection of $\mathrm{HB}$ antigen consisted of a mixture of anti-HB $\mathrm{B}_{c}$ and anti-HB $\mathrm{B}_{\mathrm{s}}$ or of either anti$\mathrm{HB}_{\mathrm{c}}$ or anti-HB $\mathrm{B}_{\mathrm{s}}$ alone.

This communication draws attention to some of the possible reasons for the apparently conflicting results reported to date on the presence or otherwise of hepatitis B antigen in human faeces and bile.

\section{Materials and Methods}

Plasma containing HB Ag and rich in Dane particles was received from a blood donor whose liver function tests were normal and who had no history of jaundice.

\section{FRACTIONATION AND CONCENTRATION}

Plasma fractionation was performed by polymer precipitation using pulverized polyethylene glycol (PEG) mw 6000, under conditions standardized for $\mathrm{pH}$, protein concentration, and ionic strength. The plasma was diluted 1:3 with Sørensen's phosphate buffer at $\mathrm{pH} 8.2$ and the mixture adjusted to $\mathrm{pH} 8.6$ by the addition of crystalline $\mathrm{Na}_{3} \mathrm{PO}_{4}$.

By the addition of PEG to the diluted plasma to make a $5 \%(\mathrm{w} / \mathrm{v})$ concentration, fibrinogen and cell debris were precipitated (fraction I), the precipitate was removed by low speed centrifugation, and the PEG concentration of the SNF was increased to 
Fig 1

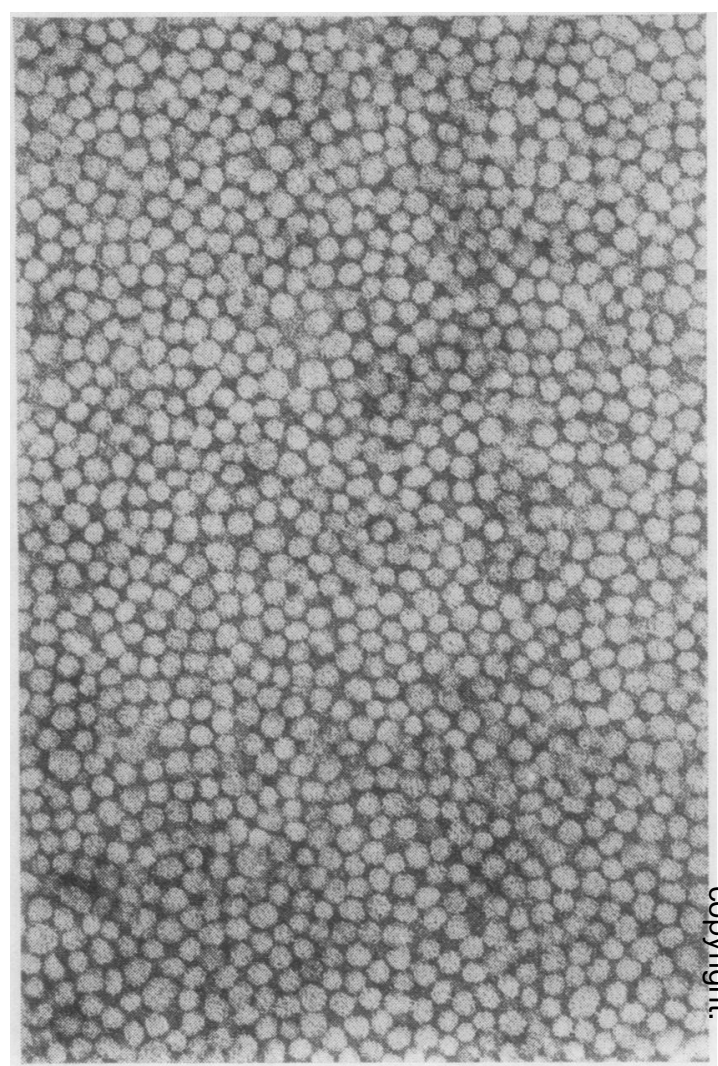

Fig 2

Fig 1 Fraction III obtained by PEG precipitation, consisting of all the Dane particles and tubules with about one third of the small spheres $(\times 100000)$.

Fig 2 Supernatant fluid after removal of fraction III, containing small spheres only. Discarded $(\times 100000)$.

$20 \%(w / v)$. This caused the formation of a further precipitate (fraction II) which was washed to remove contaminating PEG and dissolved in buffer, to the original plasma volume. This solution was refractionated by the addition of $10 \%$ PEG (w/v). The SNF contained small spheres only and was discarded. The precipitate redissolved in buffer to three fifths of the original volume constituted fraction III, the working sample.

The various fractions were examined by electron microscopy, by electrophoresis in cellulose acetate, and by one-dimensional Laurell electrophoresis in $1 \%$ agar. Exclusion chromatography on a Sepharose6B column $(20 \times 2.5 \mathrm{~cm})$ was used to separate the HB Ag from the IgG immunoglobulins. The antigencontaining fraction was mixed with $5 \% \mathrm{w} / \mathrm{v}$ sucrose solution and layered on to the Sepharose column. Monitoring of the eluate was effected by ultraviolet absorption at $280 \mathrm{~nm}$.
Standard methods were used for electron microscopy of the fractions negatively stained with $2 \%$ phosphotungstic acid and examined in a Siemens Elmiskop 1A. For immune electron microscopy the HB Ag-containing fraction was centrifuged and the pellet resuspended in $0.25 \mathrm{ml}$ phosphate-buffered saline. To this was added an equal volume of the appropriate antiserum, mixed and incubated at $37^{\circ} \mathrm{C}$ for one hour. The mixture was centrifuged and washed two or three times and then examined in the electron microscope.

The HB Ag in fraction III was treated with (a) bile from a patient with a postcholecystectomy drainage tube (the bile was $\mathrm{HB} \mathrm{Ag}$ free) at $4^{\circ} \mathrm{C}$ overnight; (b) $\mathrm{Na}$ deoxycholate $0.5 \% \mathrm{w} / \mathrm{v}$ at $4^{\circ} \mathrm{C}$ overnight; or (c) with protease, from Streptomyces griseus (Sigma) for one hour at $37^{\circ} \mathrm{C}$ at a concentration of 0.6 units $/ \mathrm{ml}$ in water. In addition, protease (at the above concentration) was added to the deoxy- 


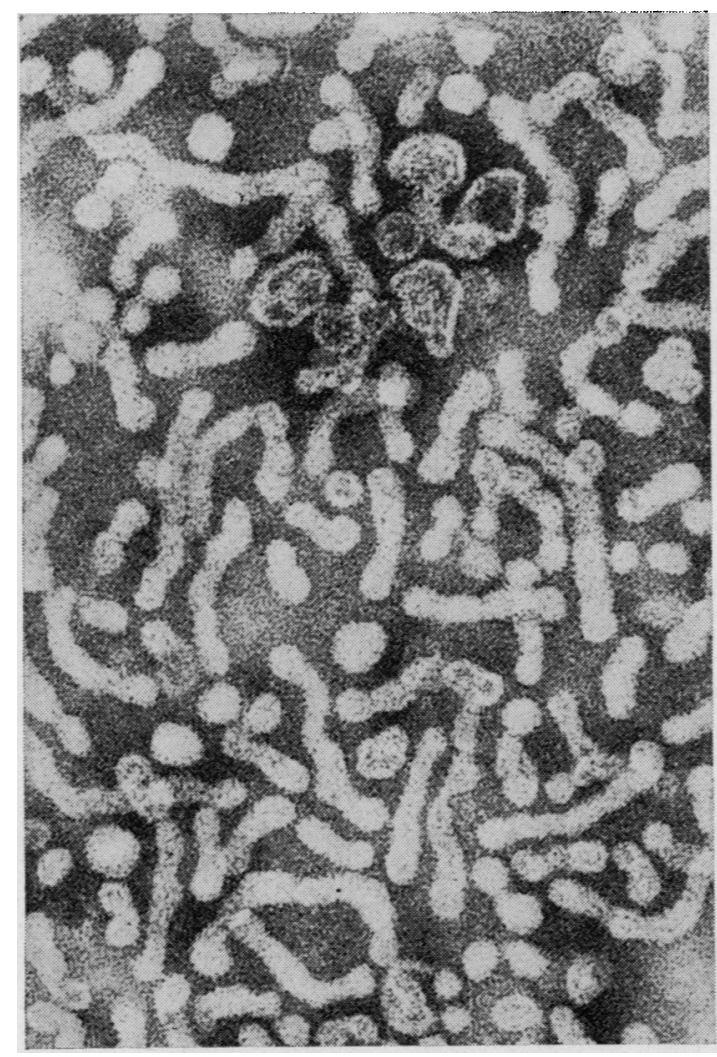

Fig 3

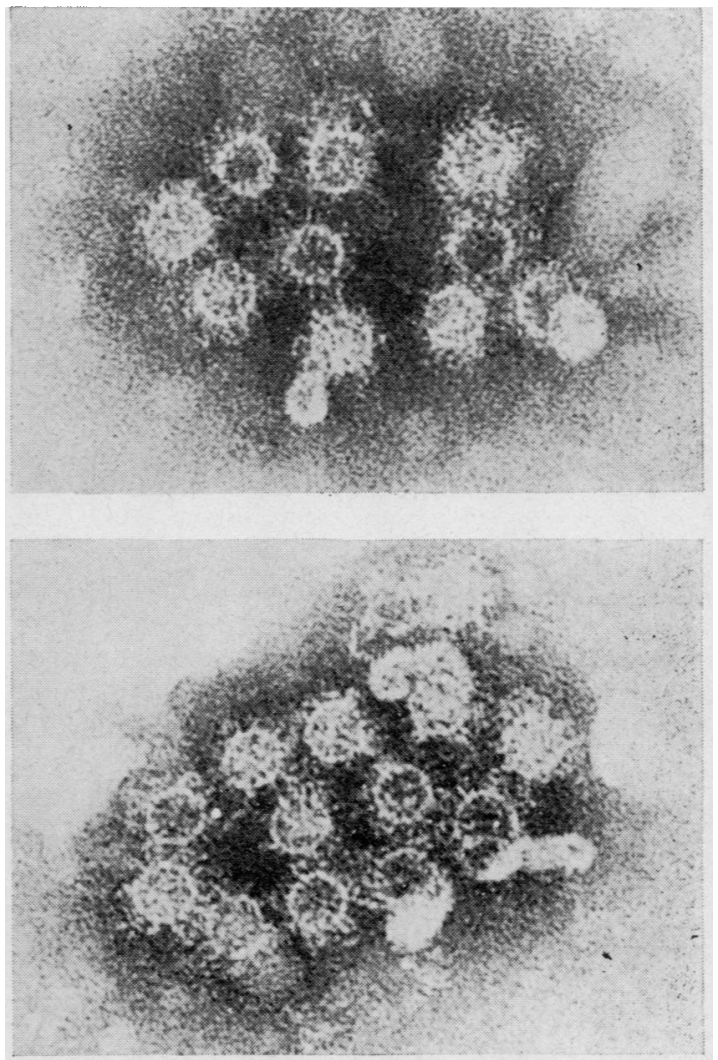

Fig 4

Fig 3 Fraction III-Sepharose treated with deoxycholate shows tubules beginning to break down into spheres and ruptured Dane coats with released cores $(\times 150$ 000).

Fig 4 By the addition of IgG anti-HBc, Dane cores surviving treatment with protease and deoxycholate could be detected as complexes $(\times 200$ 000).

cholate-treated antigen (1) at $37^{\circ} \mathrm{C}$ for one hour after removal of the antigen from the deoxycholate by centrifugation at $50000 \times g$ for one hour; (2) at $37^{\circ} \mathrm{C}$ for one hour, still in the presence of deoxycholate; or (3) at $4^{\circ} \mathrm{C}$ overnight in the presence of deoxycholate. In each case the mixture was centrifuged at $50000 \times g$ for $60 \mathrm{~min}$ in a SW 39 rotor and the pellet washed and recentrifuged before examination in the electron microscope.

\section{Results}

The donor serum contained abundant $\mathrm{HB} \mathrm{Ag}$ with many Dane particles as well as anti-HB $\mathrm{H}_{\mathrm{c}}$ demonstrated by immune electron microscopy but no anti-HBs.

Removal of fraction I left the $\mathrm{HB} \mathrm{Ag}$ in the supernatant fluid. After the addition of $20 \%$ PEG to this supernatant fluid the new precipitate (fraction II) contained the $\mathrm{HB} \mathrm{Ag}$ and the gamma globulins. This precipitate, re-dissolved in buffer and reprecipitated with $10 \%$ PEG gave rise to a precipitate (fraction III) which contained gamma globulins, all of the Dane particles and tubules but only about one-third of the small spheres (fig 1). The majority of the small spheres were present in the supernatant fluid (fig 2), which was discarded.

Fraction III was fractionated on a Sepharose-6B column which resulted in a wide separation of the IgG immunoglobulins from the antigen-rich fraction (contaminated by IgM), fraction III-Sephadex.

Treatment of the antigen-rich fraction III-Sepharose with protease at $37^{\circ} \mathrm{C}$ for one hour had no effect, detectable by electron microscopy, upon any of the HB Ag components. The particles remained separate and morphologically intact. 
Treatment of fraction III-Sepharose with bile salts (or deoxycholate) resulted in visible damage to the spheres, tubules, and Dane particles, and the Dane coats were disrupted to expose and release the inner cores but no aggregates were found (fig 3). The addition of protease to this damaged antigen in the presence of bile salts at $4^{\circ} \mathrm{C}$ or even at $37^{\circ} \mathrm{C}$ after removal of the bile salts caused no further disruption of the various components of $\mathrm{HB} \mathrm{Ag}$.

When, however, the $\mathrm{HB} \mathrm{Ag}$ in fraction IIISepharose was exposed to digestion by protease at $37^{\circ} \mathrm{C}$ in the presence of bile or deoxycholate, a dramatic change was seen. Small spheres, tubules, and Dane coats had almost completely disappeared leaving, apparently, Dane cores only intact. These were difficult to detect by standard electron microscopy methods. By the addition of IgG anti-HB $\mathrm{HB}_{\mathrm{c}}$ (from the patient's own plasma and previously removed by chromatography) many complexes of Dane cores alone were found with IgG antibody molecules arranged in a radial fashion on the surface of the particles (fig 4).

This same material exposed to anti-HB $\mathrm{B}_{\mathrm{s}}$ in onedimensional Laurell electrophoresis confirmed the dissolution and disappearance of the surface antigen, in an agar film in which an untreated sample from fraction III gave a strongly positive result.

\section{Discussion}

Although our experiments were conducted with HB antigen from serum, we believe the results may be relevant to accounting for the conflicting reports on the presence of $\mathrm{HB}$ antigen in faeces and bile.

Differential precipitation of the $\mathrm{HB}$ antigen from serum by PEG provided a useful means for eliminating large numbers of the small spheres thereby increasing the relative proportion of Dane particles and tubules in the working sample. With this we could observe, by electron microscopy, the effects of protease digestion or the effects of bile salts either singly or in combination, on all of the HB antigen components and particularly on the Dane cores.

As the presence of antibody in fraction III may have interfered with the action of the bile salts or enzymes by its adsorption to the antigens a Sepharose-6B column was used to separate the antigen from the IgG immunoglobulins. It was fortunate that our starting serum contained abundant IgG anti-HB $\mathrm{B}_{\mathrm{c}}$ but only a trace of IgM anti-HB $\mathrm{HB}_{\mathrm{c}}$ and no anti-HB s $_{s}$ either molecular species.

Digestion of the $\mathrm{HB}_{\mathrm{s}} \mathrm{Ag}$ on small spheres, tubules, and Dane coats by protease in the presence of bile or deoxycholate, was remarkably complete, leaving only core particles intact. In the absence of anti-
$\mathrm{HB}_{\mathrm{c}}$, the cores were few and widely scattered, but

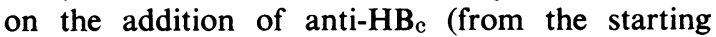
material) many complexes of cores only were easily demonstrated.

Reports on the attempts to demonstrate HB Ag in faeces or bile indicate that the techniques employed were generally of two types.

The one was a serological test (immunodiffusion in gels, complement fixation, or radioimmunoassay) using antiserum selected for its ability to recognize and identify $\mathrm{HB}_{\mathrm{s}} \mathrm{Ag}$. Such sera were from haemophilic (Cossart and Vahrmarı, 1970) or other patients, in some instances standardized by comparison with reference sera provided by Drs A. M. Prince and B. S. Blumberg (Grob and Jemelka, 1971; Cossart and Vahrman, 1970; Gust, Kaldor, and Nastasi, 1971). In two reports (Grabow and Prozesky, 1973a and 1973b) use was made of baboon antiserum to human HB Ag from human serum and in another a commercially prepared antiserum distributed in a diagnostic kit (Piazza, Di Stasio, Maio, and Marzano 1973).

In the other type of procedure antiserum was used in immune electron microscopy. Cross, Waugh, Ferris, Gust, and Kaldor (1971) demonstrated aggregates of particles in faecal extracts which re sembled damaged small spheres and disrupted Dane particles of HB Ag. But despite their morphologicab. similarity, the particles were serologically distince from their HB Ag counterparts in human sera. The antiserum used in their experiment was raised in rabbits to an antigen $F$ derived from a faecal extract, reacted with Dane particles but not with the small spheres in human serum. Antisera prepared in guinea pigs to the small spheres of human HB Ag failed to aggregate the small particles in the faeces. Ferris (1972) found complexes of $15-25 \mathrm{~nm}$ particles in a faecal extract with anti-F serum, but these particles bore little resemblance to the small spheres of $\mathrm{HB} \mathrm{Ag}$.

Two reports refer to the destructive effects of faecal extracts on the HB antigen. Piazza, di Stasio, Maio, and Marzano (1973) showed that homogenates of human faeces or intestinal mucosa incubated with $\mathrm{HB}$ antigen for two hours at $37^{\circ} \mathrm{C}$ (but not at $2^{\circ} \mathrm{C}$ ) were able to render antigen inactive in the complement-fixation test. It was found by Grabow and Prozesky (1973a) that the addition of HB Ag to faecal extracts resulted in the conversion of a positive serological test for $\mathrm{HB} \mathrm{Ag}$ to a negative one by a heat-labile agent active at $37^{\circ} \mathrm{C}$ but not at $4^{\circ} \mathrm{C}$. There is nothing in these two reports that could not be explained by the digestion of $\mathrm{HB}_{\mathrm{s}} \mathrm{Ag}$ by proteolytic enzymes in the presence of bile salts. None of the above reports mention the use of anti $\mathbf{H B}_{\mathrm{c}}$ and in none of the EM studies were complexes of cores reported. 
Our observations on the effect of detergent and proteolytic enzymes on the components of $\mathrm{HB}$ antigen in serum indicate that under the conditions of these experiments the surface antigen, $\mathrm{HB}_{\mathrm{s}} \mathrm{Ag}$, of the small spheres, tubules, and Dane particle coats was virtually completely destroyed leaving the Dane cores morphologically and antigenically undamaged and able to adsorb IgG anti- $\mathrm{HB}_{\mathrm{c}}$ in a radial fashion identical with that described by Stannard, Polson, Kipps, and Parker (1973). It is perhaps not surprising, therefore, that some of the reports recorded negative results (Cossart and Vahrman, 1970; Gust, Kaldor, and Nastasi, 1971; Grabow and Prozesky, 1973a). Some support for our findings that bile salts alone did not eliminate the surface antigen but proteolytic enzymes in the presence of bile did is provided by the reports by Serpeau, Mannoni, Dhumeaux, and Berthelot (1971) who found $\mathrm{HB} \mathrm{Ag}$ in bile but not in duodenal juice, and by Akdamar, Maumus, Epps, Leach, and Warren (1971) who found the antigen in bile but not in gastric juice.

It appears therefore that in the search for $\mathrm{HB} \mathbf{A g}$ in faeces or bile, the technique of immune electron microscopy should be employed so that the relatively small number of cores may be detected using anti$\mathrm{HB}_{\mathrm{c}}$ sera, and that procedures however sensitive or sophisticated for the detection of $\mathrm{HB}_{\mathbf{s}} \mathrm{Ag}$ may well be inappropriate.

We thank Dr E. R. Rudman of the Western Pro- vince Blood Transfusion Service, Cape Town, for supplying us with antigen-rich plasma, and $\mathrm{Dr} \mathrm{A}$. Polson for his advice.

References

Akdamar, K. A., Maumus, L., Epps, A. C., Leach, R., and Warren, S. (1971). S.H. antigen in bile. (Letter) Lancet, 1, 909.

Almeida, J. D., Rubenstein, D., and Stott, E. J. (1971). New antigenantibody system in Australia-antigen-positive hepatitis. Lancet, 2, 1225-1227.

Cossart, Y. E., and Vahrman, J. (1970). Studies of Australia-SH antigen in sporadic hepatitis in London. Brit. med. J., 1, 403405.

Cross, G. F., Waugh, M., Ferris, A. A., Gust, I. D., and Kaldor, J. (1971). Virus-like particles associated with a faecal antigen from hepatitis patients and with Australia antigen. Aust.J. exp. Biol. med. Sci., 49, 1-9.

Ferris, A. A. (1972). Antigen in infectious hepatitis. Brit. med. Bull., 28, $131-133$.

Grabow, W. O. K., and Prozesky, O. W. (1973a). S.A. Soc. Path. Annual Congress Sept. 1973.

Grabow, W. O. K., and Prozesky, O. W. (1973b). Isolation and purification of hepatitis-associated antigen by affinity chromatography with baboon antiserum. J. infect. Dis., 127, 183-186.

Grob, P. J., and Jemelka, H. (1971). Faecal S.H. (Australia) antigen in acute hepatitis. Lancet, 1, 206-208.

Gust, I. D., Kaldor, J., and Nastasi, M. (1971). Absence of Au antigen in faeces of patients with Au-positive sera. (Letter) Lancet, 1, 797.

Huang, S. N., and Groh, V. (1973). Immunoagglutination electron microscopic study on virus-like particles and Australia antigen in liver tissue. Lab. Invest., 29, 353-366.

Piazza, M., Di Stasio, G., Maio, G., and Marzano, L. A. (1973). Hepatitis $B$ antigen inhibitor in human faeces and intestinal mucosa. Brit. med. J., 2, 334-337.

Serpeau, D., Mannoni, P., Dhumeaux, D., and Berthelot, P. (1971). Hepatitis-associated antigen in human bile. (Letter) Lancet, 2 , 1266.

Stannard, L. M., Polson, A., Kipps, A., and Parker, J. R. (1973). Two antigen-antibody systems in serum hepatitis: preparation of immunoglobulins and their reaction with Australia antigen and particles in liver cell homogenates. Microbios., 8, 87-100. 